\title{
Culture matérielle du christianisme égyptien : les déserts Occidental et Oriental (2020)
}

Ganub Qasr al-Aguz

Victor Ghica, Rhiannon Williams, Zulema Barahona Mendieta and Valérie Schram

\section{(2) OpenEdition}

\section{Journals}

Electronic version

URL: https://journals.openedition.org/baefe/2849

DOI: $10.4000 /$ baefe.2849

ISSN: 2732-687X

Publisher

ResEFE

Electronic reference

Victor Ghica, Rhiannon Williams, Zulema Barahona Mendieta and Valérie Schram, "Culture matérielle du christianisme égyptien : les déserts Occidental et Oriental (2020)" [Note of archaeological project] Bulletin archéologique des Écoles françaises à l'étranger [Online], Egypt, Online since 30 May 2021 connection on 25 July 2021. URL: http://journals.openedition.org/baefe/2849 ; DOI: https://doi.org/ $10.4000 /$ baefe. 2849

This text was automatically generated on 25 July 2021.

\section{cc) (†) $\ominus$}

Le Bulletin archéologique des Écoles françaises à l'étranger est mise à disposition selon les termes de la Licence Creative Commons Attribution - Pas d'Utilisation Commerciale - Pas de Modification 4.0 International. 


\section{Culture matérielle du christianisme égyptien : les déserts Occidental et Oriental (2020)}

Ganub Qasr al-Aguz

Victor Ghica, Rhiannon Williams, Zulema Barahona Mendieta and Valérie Schram

\section{AUTHOR'S NOTE}

Année de la campagne : 2020 (12 décembre - 24 décembre)

Autorité nationale présente : The Ministry of Tourism and Antiquities (MoTA) was represented by Sharif Muhammad Sharif

Numéro et intitulé de l'opération de terrain : 17163 - Culture matérielle du christianisme égyptien : les déserts Occidental et Oriental

Composition de l'équipe de terrain : L'équipe de terrain était composée de Victor Ghica (archéologue, MF Norwegian School of Theology, Religion and Society, Oslo), Rhiannon Williams (archéologue, MF Norwegian School of Theology, Religion and Society, Oslo), Valérie Schram (papyrologue, MF Norwegian School of Theology, Religion and Society, Oslo), Zulema Barahona Mendieta (céramologue, Universität Basel), Andrea Di Miceli (archéologue, ArcheoRes), Mennat-Allah El Dorry (archéobotaniste, MoTA), Mohamed Gaber (topographe, Ifao), Mohamed Abd Elaziz (spécialiste 3D, CEAlex/Indiana University), Per Rathsman (architecte, Rathsman Arkitektkontor AB, Karlstad).

Partenariats institutionnels : MF Norwegian School of Theology, Religion and Society, Oslo, Norway.

Organismes financeurs : MF Norwegian School of Theology, Religion and Society (financement ERC). 


\section{Excavations at Ganub Qasr al-Aguz}

1 This year's season took place between 12-24 December 2020. The scientific team was composed of Victor Ghica and Rhiannon Williams. The COVID-19 restrictions did not allow the eight other members of the team to take part into the fieldwork. The Supreme Council of Antiquities was represented by the inspector Sharif Muhammad Sharif. The 28 workmen from Bahariyya were directed by the rais Muhammad Nur.

Due to the late approval of the excavation permits and the absence from the field of most of the team because of COVID-19 related travel restrictions, the field operations had to be entirely reorganised. The 2020 season was thus adjusted to the need of studying remotely the material unearthed this year, while attempting to finalise the dig of the site.

3 Four sectors were studied this year, GQA3, GQA4, GQA5 and GQA6 (fig. 1), three of which (GQA3, GQA5 and GQA6) had been test-excavated by our team in 2013. Because of their size and state of preservation, most of the effort was put into the large sectors GQA5 and GQA6.

Fig. 1. Satellite photo showing Tell Ganub Qasr al-Aguz and the area between Qasr al-Aguz (to the north) and Gabal Hafhuf (to the south) (V. Ghica, on a GeoEye-1 satellite; photo taken on October 9, 2013).

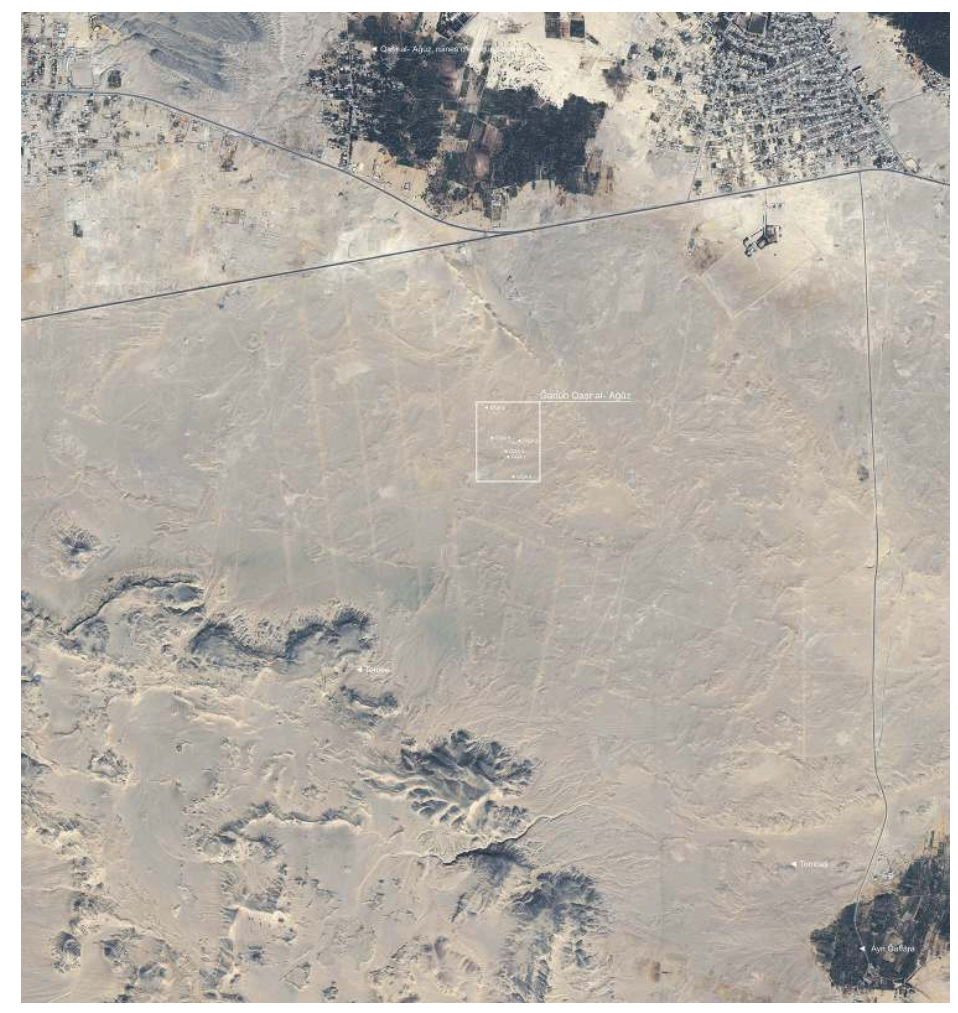

(c) Ifao. 17163_2020_NDMCN_001

4 In the area QGA6 (fig. 2), only one room had been partly excavated in the 2013 season. In 2020, 18 additional rooms were uncovered in this sector. Although most spaces excavated by our team in this sector had been previously cleared by looters, several undisturbed archaeological contexts could be identified. These unpolluted layers allowed for establishing the stratigraphic sequences prior to the looting of the site. The 
original stratigraphy recovered in GQA5 and GQA6 is identical to that observed in GQA1 and GQA2, where the elevation of the walls is similar.

Fig. 2. Sector GQA6 at the end of the 2020 excavation season (V. Ghica).

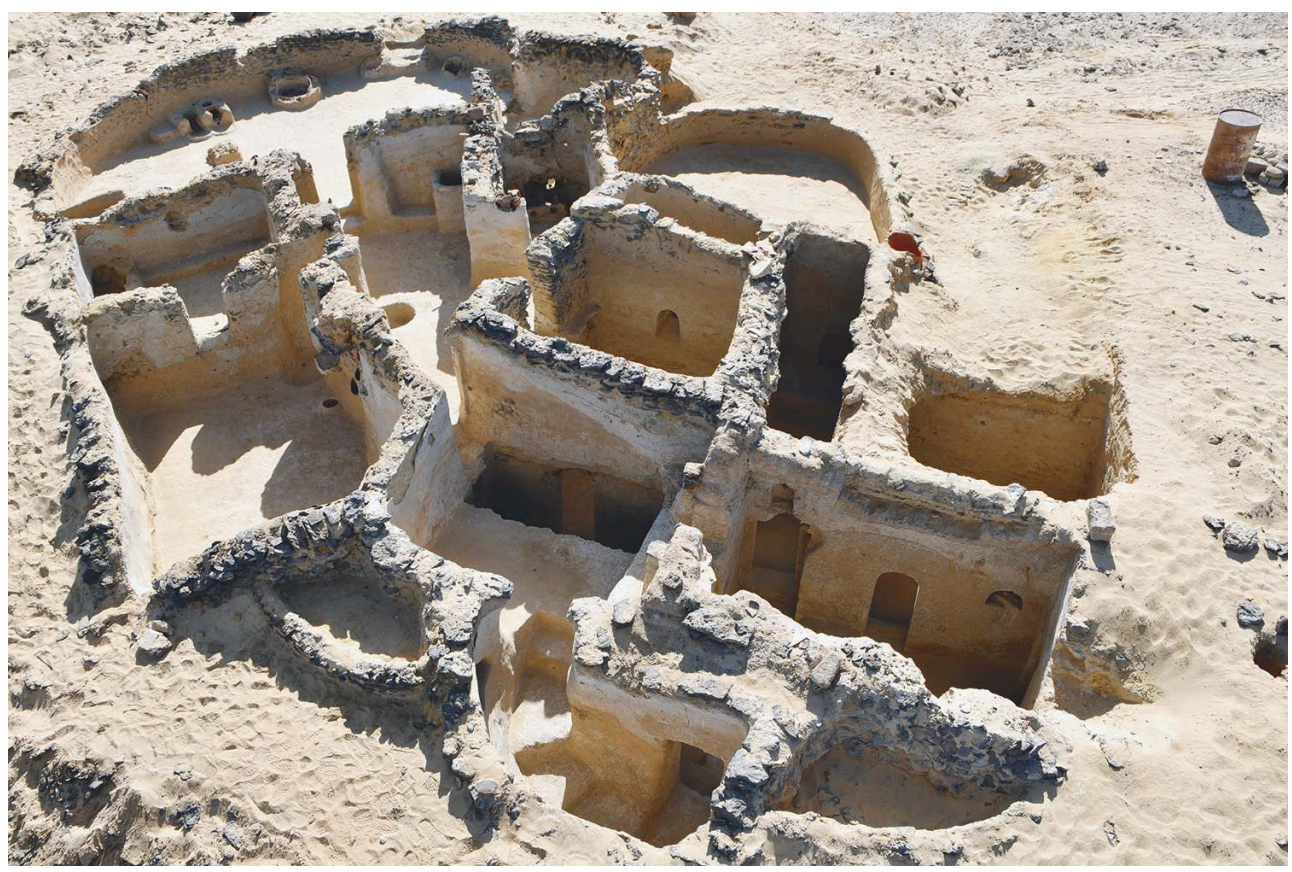

(C) Ifao. 17163_2020_NDMPF_001

5 The study of the material found in the 19 rooms of the sector GQA6 (fig. 3) as well as the analysis of the wall joints, wall coatings, orientation of spaces, building techniques, as well as the relationships between walls and floors led us to establish the following phases of construction for the area GQA6:

- Phase 1: P6, P16, P17, P12 (N-S segment), P14, P15;

- Phase 2: P5, P8, P7, P18, P3/P4/P10 (as one single space), P11, P9, P13;

- Phase 3: P1, P2;

- Phase 4: P19;

- Phase 5: P4 receives an eastern wall; the bay in the southern part of P10 is walled, which turns this space into a proper room; P18 is blocked by a wall in the north, which continues the corridor P12 with a E-W oriented segment. 
Fig. 3. Orthophoto of sector QGA6 (M. Abd Elaziz, V. Ghica).

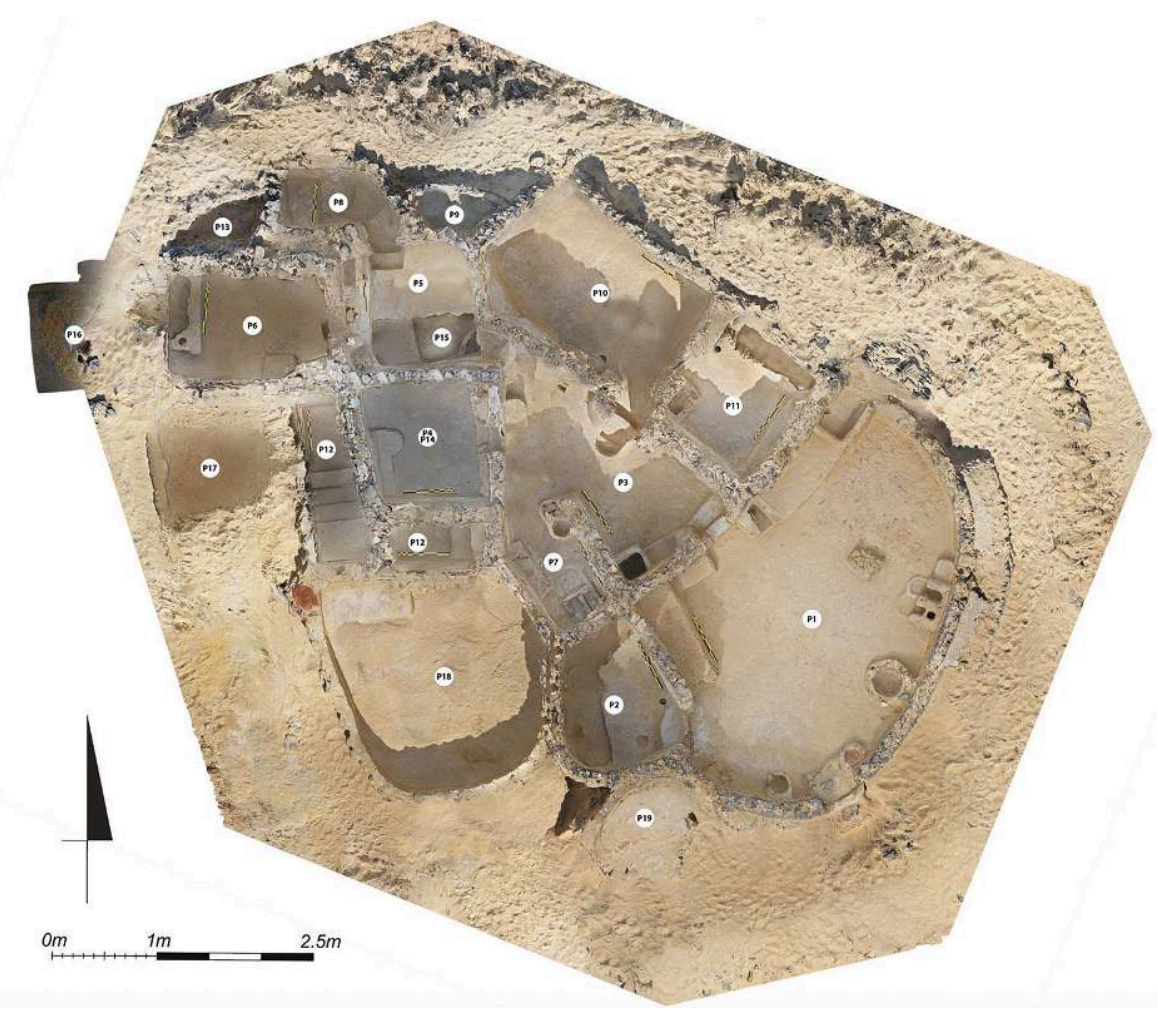

(C) Ifao. 17163_2020_NDMCN_002

6 The extension of the initial nucleus of the sector GQA6 (phase 1), which is mostly cut into the bedrock, occurs by agglutination of built spaces west- and southward in three successive phases.

7 The rooms built in phase 1 comprise: a church (P6), semi-excavated in the bedrock; an independent apartment (P14 and P15), again semi-excavated in the substrate; two annex rooms attached to P6 (P16 and P17), entirely cut into the bedrock; and a corridor/vestibule (the N-S segment of P12). In phase 1, the entrance into the original rock-cut complex was at the southern end of the corridor P12 (N-S segment). The original building complex (GQA6 construction phase 1) was oriented N/S, with the easternmost walls displaying a slight deviation from the N/S axis. The plan of the complex in this phase was rectangular, or sub-rectangular if one takes into account P16, which protrudes towards the west, but underground.

In phase 2, un upper floor is built atop rooms P14 and P15 (these upper floors becoming the spaces $\mathrm{P} 4$ and $\mathrm{P} 5)$ as well as a large central space ( $\mathrm{P} 3 / \mathrm{P} 4 / \mathrm{P} 10$, which was one single distributing central room), a kitchen (P7), a large courtyard (P18, whose low walls hint to a roofless area, shielded from the wind by its position to the south of the complex), a sleeping room (P11), a stepped corridor (P8) allowing for P6 to be accessed from P5, and two buttresses (P9, P13) that protected the liturgical area. The construction phase 2 responds in all likelihood to the need of accommodating more occupants. The N-W/S-E orientation of the construction block built in phase 2 as well as the addition of the spaces $\mathrm{P} 9$ and $\mathrm{P} 13$, whose function seems to be that of protecting the northern walls of rooms P5 and P6 from the dominant winds, suggests that the builders of GQA6-phase 2 
attempt to mitigate the problem of the wind erosion. The entrance into GQA6 in this phase was in the N-E/S-W-running wall of $\mathrm{P} 3$, so protected from the northern winds.

Phase 3, in return, is an enlargement geared towards storing food supplies. Thus, P1 brings to the complex a large storage and food preparation area, fitted with a stove, a dolium and two storage containers embedded in the floor and flanking the external doorway. P2 was perhaps also utilised for storing, although some of its features, along with parts of the floor, were destroyed by modern plunderers, which makes the identification of its function difficult. The entrance into GQA6 in this phase was in the semicircular eastern wall of P1, again sheltered from the northern winds.

The construction of P19 marks the last building phase (phase 4). With its floor $70 \mathrm{~cm}$ higher than the floor of the adjacent $\mathrm{P} 1$ and a high doorway between these two rooms as well as a step in front of it, P19 is probably to be understood as an annex to P1. The state of preservation of P19 is too bad (the S-E half of the room, including the floor, is destroyed) to allow ascertaining the function of this space.

11 In phase 5, several spaces are reorganised. The sealing off of the courtyard P18 might denote a reduction of the number of inhabitants in GQA6, but the creation of P4 through the construction of its eastern wall and the further compartmentalising of the initial space P3/P4/P10 that results in the blocking of the bay in the southern part of P10 point towards a need to create separate living spaces.

The ceramic coming from the sector GQA6 tends to confirm the functions of the spaces described above. Liquid storage containers as well as cooking pots and table vessel dominate the repertoire. The facies of the pottery points towards a final occupation of the sector in the 5th or 6th centuries AD. At this stage, with the ceramic still not studied in detail and the organic samples yet to be carbon-dated, no precise abandonment date can be proposed. Nevertheless, the abandonment in the 5th-6th century is supported by the content of the four ostraca found in GQA6, all in Greek, as well as by the 36 Greek dipinti that adorn rooms P6, P5, P8 and P10 (fig. 4). Painted on two different layers of coating, these inscriptions contain passages from the New Testament and quotes form patristic texts (Ephrem the Syrian, Evagrius Ponticus, Athanasius of Alexandria), and ascertain the liturgical function of the chapel P6 (a dipinto in the central niche contains 1 Cor 11:26; fig. 5), but possibly also of P5 and P8. Indeed, $\mathrm{P} 5$ might have functioned, as indicated also by the opening in the wall between P6 and P5 as well as by the corridor P8, as the sanctuary - although a sui generis one - of the church P6 extended in phase 2. As for the Greek ostraca found in P1, P2, P3 and P10, they contain: a request of supply (inv. 202017); a very fragmentary letter (inv. 202088); a text of uncertain content, perhaps a writing exercise (inv. 202025); and, finally, a monk's letter to abba Kosmas (inv. 202024). The latter is datable to the 5th century and is likely addressed to the same Kosmas featuring in O.Bahria Div. 1 (= SB 20 14923). 
Fig. 4. Dipinti in room P8 in sector GQA6 (R. Williams).

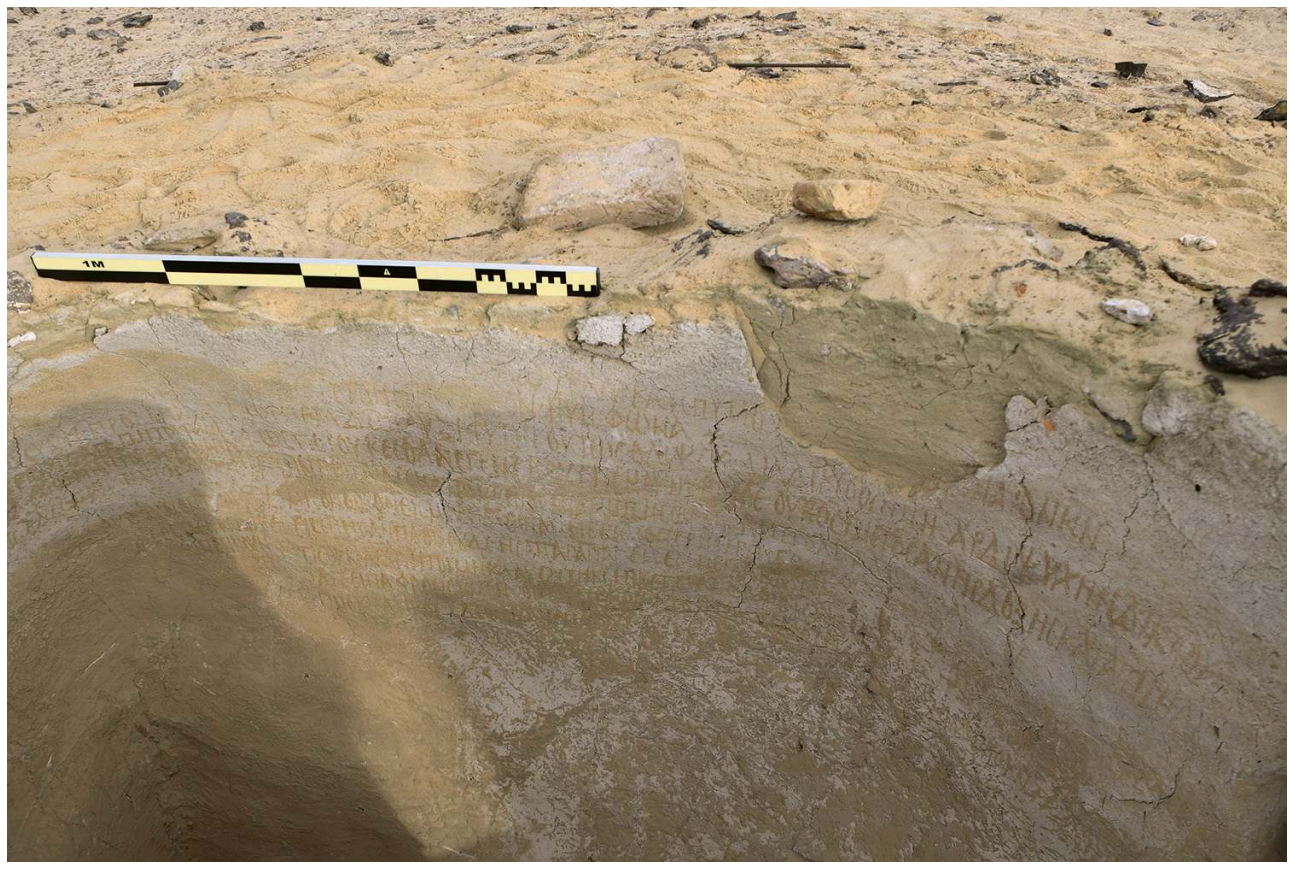

(c) Ifao. 17163_2020_NDMPF_002

Fig. 5. Wall east of room P6 in GQA6 (R. Williams).

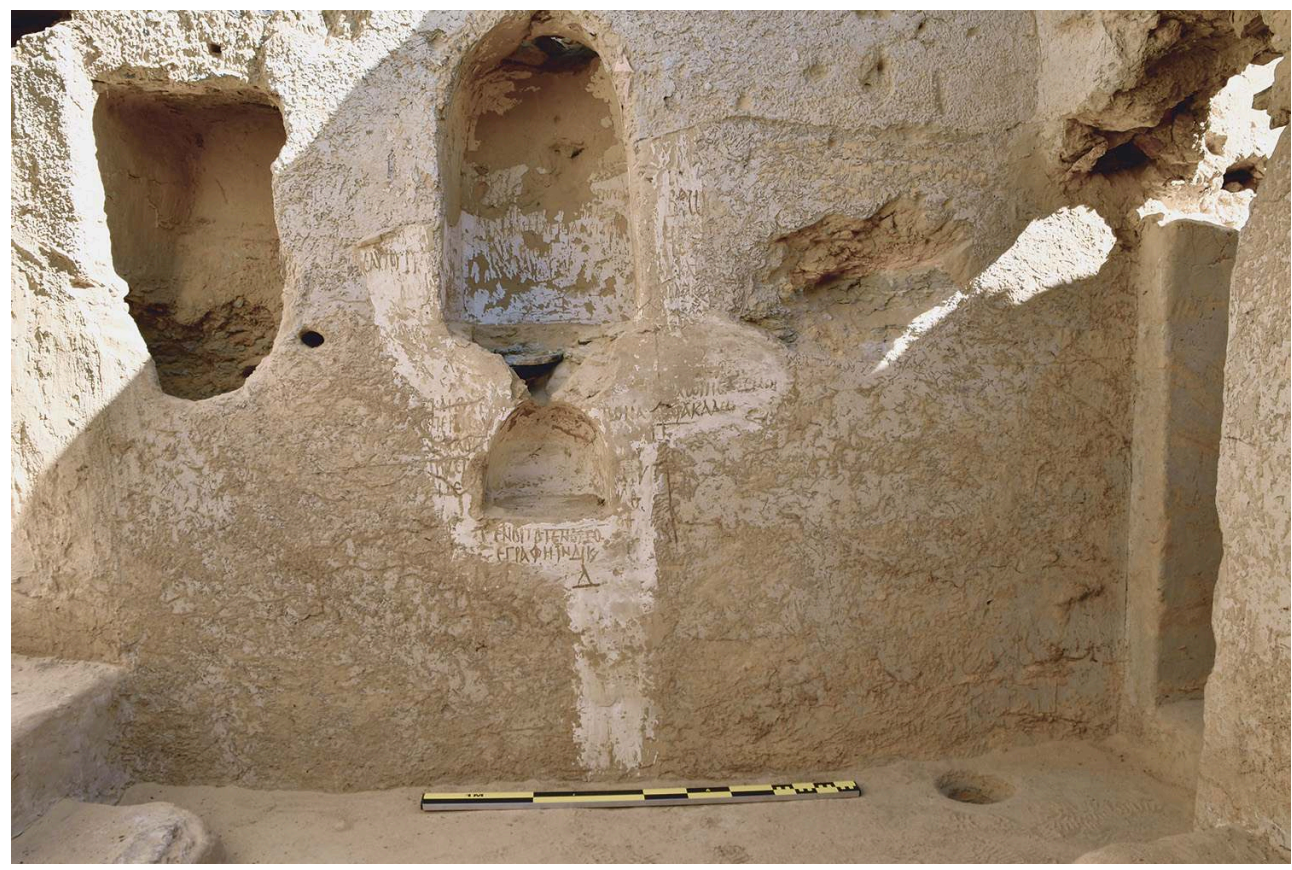

(C) Ifao. 17163_2020_NDMPF_003

Sector GQA5 comprises 9 rooms (fig. 6). Out of these, only one (P1) had been excavated in the 2013 season. This sector had been plundered sometime between our first and second excavation seasons (2009-2013). As a result, half of the rooms of GQA5 (P1, P2, P5, P3) lost their original stratigraphy. These four rooms are entirely (P1, P2, P5) or almost entirely (P3) cut into the geological substrate and served, likely, as sleeping (P2, 
P5) and storing rooms (P1). P3 was a central distributing space, which gave access to all the other rooms or groups of rooms (such as the group P1-P2-P5). Attached to P3, was P8, a small storing space, with a floor higher than the one of P3 and provided with stairs that led likely to the outside. Large storage vessels, broken, were found in this room confirming its role. Rooms $\mathrm{P} 4$ and $\mathrm{P} 6$, built to the south of the central space P3 had both cooking installations. Finally, P9, constructed to the south of P4 and P6, is a kitchen built at a later stage. The pottery found in GQA5, particularly a LRA 1A amphora (Egloff 169, dated to the end of the 4th or 5th century) and several small siga-flasks (dated in Bahariyya to the end of the 4th or to the 5th century ${ }^{1}$ ), indicate that this sector (except, perhaps, the later addition P9) was abandoned during the 5th century. The construction typology of the troglodytic area (P1, P2, P5) might suggest, by analogy with its correspondent in GQA1 (GQA1 phase 1), a 4th century date. Radiocarbon dating of organic material collected in relevant layers will refine the chronology of the occupation in GQA5. No inscribed material was found in this sector.

Fig. 6. Orthophoto of sector QGA5 (A. Di Miceli, V. Ghica).

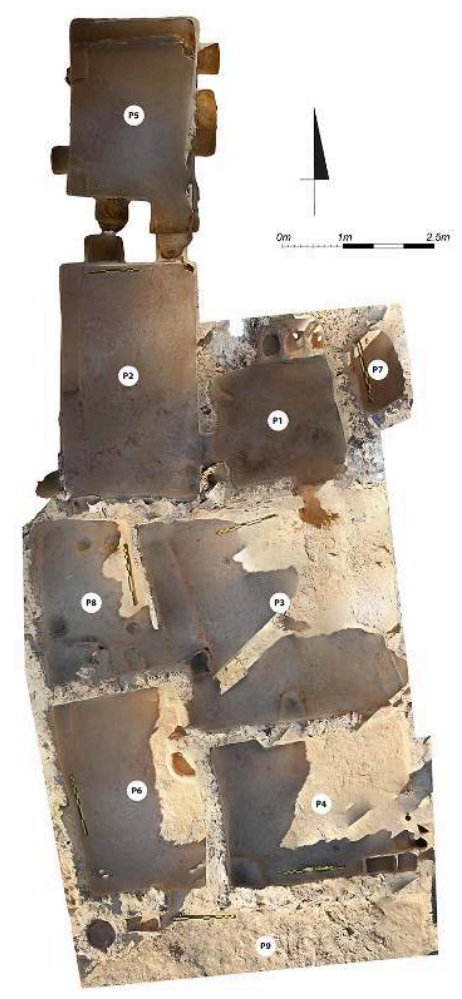

(C) Ifao. 17163_2020_NDMCN_003

In the sector GQA3, we proceeded to two sondages in the northern-most part of the large enclosure (P4). Limited excavation time did not allow for further examination. The larger test trench revealed what appears to be a N/S oriented well of a subrectangular plan, the original dimension of which were probably $3.2 \times 2.4 \mathrm{~m}$. The well was cleared to a depth of $1.8 \mathrm{~m}$. This trench suggests thus that GQA3 - the sector of the site located at the lowest altitude - sheltered the water well used by the community of Ganub Qasr al-Aguz. Animal remains found within the large enclosure (P4) in an occupation layer (SU3042) imply that this sector was also used for animal husbandry, 
notably for goats. The three rooms of this sector excavated during the 2013 season will therefore be reinterpreted in the light of these new results.

In the sector GQA4, which is the southern-most of the archaeological site, only limited test excavations were carried out. They revealed 3 rooms (fig. 7), built of clay and basalt slabs but also ashlar, of which one has a semi-circular plan, typical of the later structures seen in GQA1 and GQA6, all of which are characterised by a grape-shaped agglutination of rooms.

Fig. 7. Orthophoto of sector GQA4 (V. Ghica).

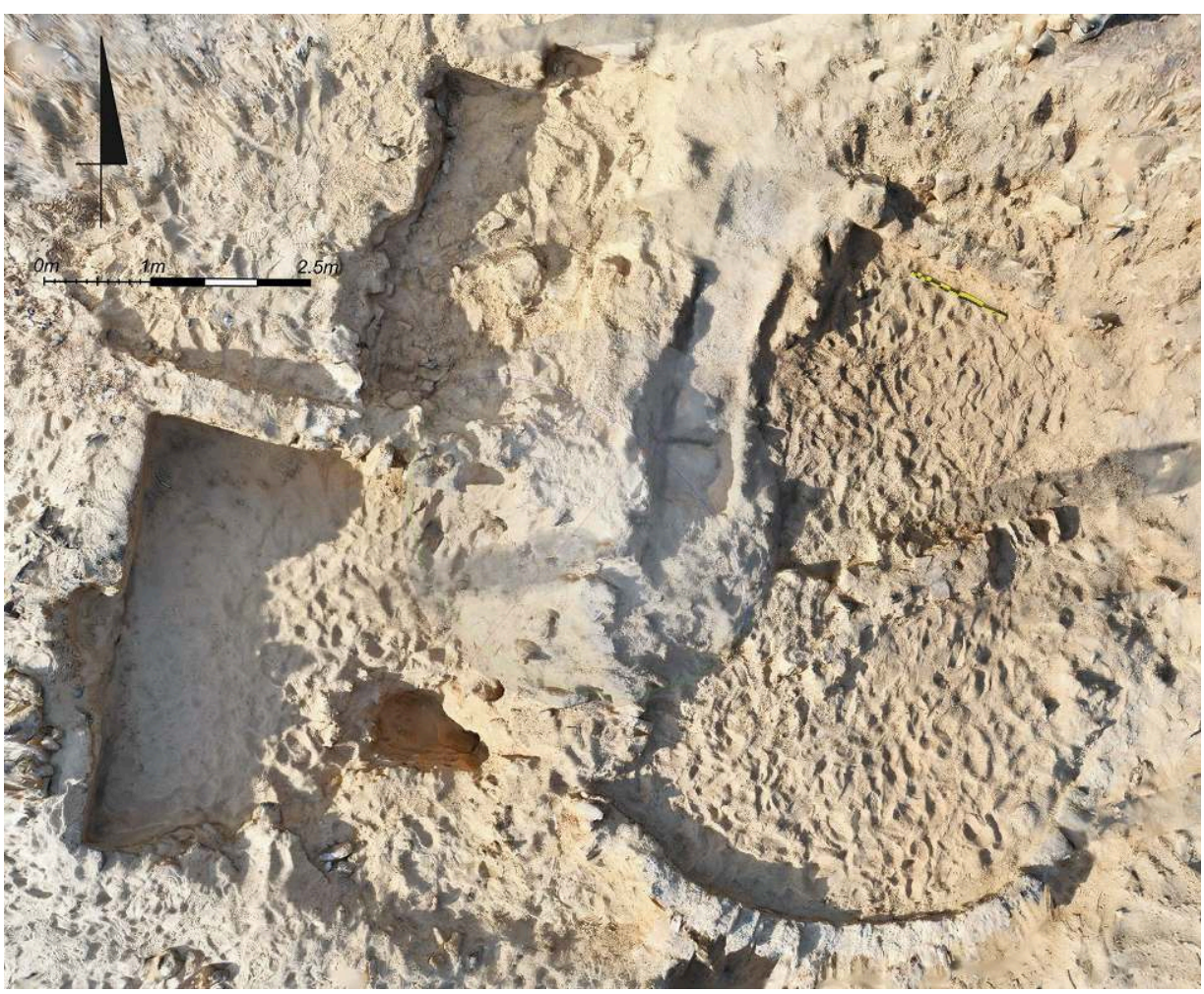

(C) Ifao. 17163_2020_NDMCN_004

\section{Post-excavation}

As most of the archaeological material could not be studied in situ, its analysis was postponed to 2021 (for ceramic and glass) and the beginning of 2022 (for botanical remains). The epigraphic and ostracological material has been studied off site by Valérie Schram as part of a DEChriM work-package.

Photogrammetric modeling of the latest excavation stages on sectors GQA5, GQA6, GQA3 and GQA4 could be carried out off site. The mapping of each sector was thus realised from orthophotos generated in Agisoft Metashape Pro (Victor Ghica, Mohamed Abd Elaziz, Andrea Di Miceli). In addition, a full contour map of the archaeological area of Ganub Qasr al-Aguz was generated on the basis of a DEM file extracted from GoogleEarth, which was then treated in QGIS. 


\section{Publications}

18 Victor Ghica, "Ganoub Qasr el-Agouz (oasis de Bahariya)", in Laurent Coulon, Mélanie Cressent (éd.), Archéologie Française en Égypte. Recherche, coopération, innovation, BiGen 59, Le Caire, Ifao, 2019, p. 236-241.

\section{BIBLIOGRAPHY}

COLIN, LAISNEY, MARCHAND 2000

Frédéric Colin, Damien Laisney, Sylvie Marchand, "Qaret el-Toub : un fort romain et une nécropole pharaonique. Prospection archéologique dans l'oasis de Bahariya 1999", BIFAO 100, 2000, pp. 145-192.

\section{NOTES}

1. Colin, Laisney, Marchand 2000, figs 50-52.

INDEX

Subjects: IFAO

Year of Investigation: 2020

\section{AUTHORS}

\section{VICTOR GHICA}

Archéologue, MF Norwegian School of Theology, Religion and Society, Oslo

\section{RHIANNON WILLIAMS}

Archéologue, MF Norwegian School of Theology, Religion and Society, Oslo

\section{ZULEMA BARAHONA MENDIETA}

Céramologue, Universität Basel

\section{VALÉRIE SCHRAM}

Archéologue, MF Norwegian School of Theology, Religion and Society, Oslo 